\title{
New directions in cardiac stem cell therapy: An update for clinicians
}

\author{
Sarabjeet Singh, Mohammad Kashif, Neil Bhambi, Rajendra R. Makkar, James S. Forrester \\ Cedars-Sinai Medical Center, Los Angeles, USA \\ Email: kashifrazzak@gmail.com
}

Received 14 March 2012; revised 23 April 2012; accepted 2 May 2012

\begin{abstract}
The emergence of cardiac stem cell therapy can be traced to late 2001, when studies in small animal models of myocardial infarction suggested that stem cells could engraft, proliferate, and regenerate myocardium. Subsequent animal laboratory studies showed improved cardiac function, perfusion and survival compared to controls (Figure 1). Within two years, the first clinical trials of stem cell therapy began to appear, and we now have several trials of intracoronary infusion of bone marrow cells with more than one year follow-up. Although this clinical therapy has proven to be safe, the magnitude of improvement in objective measures like ejection fraction has been modest, and the therapy has not entered clinical practice. In the absence of a large prospective randomized trial, the field has moved back to the laboratory. This manuscript aims to provide clinicians with a broad overview of this complex field by briefly reviewing the existing status of clinical myocardial regeneration therapy, then describing selected examples from the laboratory research approaches that may provide a platform for new and potentially increasingly effective clinical strategies.
\end{abstract}

Keywords: Cardiac Stem Cells; Myocardial

Regeneration; Therapy

\section{THE CURRENT STATUS OF CLINICAL CARDIAC STEM CELL THERAPY}

The major clinical trials of intracoronary or transendocardial delivery of autologous bone marrow-derived progenitor cells are shown in Table 1. The available data has significant limitations. Most of these studies had small enrollment [maximum: 204 patients inthe Reinfusion of Enriched Progenitor Cellsand Infarct Remodeling in Acute Myocardial Infarction (REPAIRAMI)] [1,2]. The trials differed substantially with respect to cell source, number and volume, surface markers, mode of processing, method and timing of delivery, and the use of adjunctive therapy. In some of the trials the control group also exhibited slight improvement in cardiac function over time [2-5]. The largest randomized trial, REPAIRAMI, reported both improved ejection fraction and clinical benefit following intracoronary autologous bone marrow cell therapy at 12 month follow-up [1]. One meta-analysis of bone marrow cell (BMC) infusion in patients with acute myocardial infarction [6] with median follow-up of 6 months found a significant absolute improvement in LVEF of 3.0\% (95\% confidence interval: $1.9 \%$ to $4.1 \%, \mathrm{p}<0.00001$ ) for treated patients compared to controls. Similarly, LV end-systolic volume was reduced in patients receiving cell therapy by $-7.4 \mathrm{ml}(95 \%$ confidence interval: -12.2 to $-2.7 \mathrm{ml}, \mathrm{p}<0.002)$ compared to controls. Results at one year and beyond are inconsistent, however, since some studies report sustained improvement whereas others did not $[7,8]$. The only 5-year follow-up comes from an early nonrandomized trial of 62 patients [9] who were compared to 62 patients who refused cell transplantation. At 5 years, ejection fraction was $56.2 \% \pm 9 \%$ in the treated group versus $48.9 \% \pm 8.3 \%$ in controls, with a significantly better 5 year survival. None of the clinical trials have provided evidence of significant myocardial regeneration. Further, several laboratories have found that conditioned media without any cells can reproduce much of the benefit of MSCs. We may draw the reasonable conclusion that clinical stem cell therapy is safe, and confers a modest functional and clinical improvement, most likely through paracrine effects of the injected cells.

The original and continuing long term goal of stem cell therapy, of course, remains true myocardial regeneration. Although the barriers to this goal are many, the most important may be the environment into which the cells are delivered, and the nature of the cells utilized. In addition to the broad basic field of stem cell growth and differentiation, cardiac stem research is now being directed at improving cell survival, persistence and proliferation. 
Table 1. Studies evaluating intracoronary stem cell transplantation.

\begin{tabular}{|c|c|c|c|c|c|c|c|c|c|c|}
\hline $\begin{array}{c}\text { Study } \\
\text { (Reference) }\end{array}$ & $\begin{array}{l}\text { No of } \\
\text { subjects }\end{array}$ & $\begin{array}{l}\text { Age } \\
\text { (Years) }\end{array}$ & $\begin{array}{l}\text { Men } \\
(\%)\end{array}$ & Cell type & $\begin{array}{l}\text { Volume of } \\
\text { injected } \\
\text { cells (ml) }\end{array}$ & $\begin{array}{l}\text { Number of } \\
\text { injected cells }\end{array}$ & $\begin{array}{l}\text { LVEF (\%) } \\
\text { control group } \\
\text { (Baseline) }\end{array}$ & $\begin{array}{l}\text { LVEF (\%) } \\
\text { control group } \\
\text { (Follow up) }\end{array}$ & $\begin{array}{l}\text { LVEF (\%) } \\
\text { transplant } \\
\text { group } \\
\text { (Baseline) }\end{array}$ & $\begin{array}{l}\text { LVEF (\%) } \\
\text { transplant } \\
\text { group } \\
\text { (Follow up) }\end{array}$ \\
\hline Strauer [44] & 20 & 50 & 92.5 & BMC & 20 & $46 \times 10^{6}$ & $60 \pm 7$ & $64 \pm 7$ & $57 \pm 8$ & $62 \pm 10$ \\
\hline Bartunek [45] & 35 & 54 & 91 & $\mathrm{BMC}$ & $15-20$ & $\mathrm{NP}$ & $44.3 \pm 3.1$ & $48.6 \pm 3.6$ & $45 \pm 2.5$ & $52.1 \pm 3.5$ \\
\hline Jannsens [4] & 67 & 57 & 82 & BMC & 10 & $304 \times 10^{6}$ & $46.9 \pm 8.2$ & $49.1 \pm 10.7$ & $48.5 \pm 7.2$ & $51.8 \pm 8 . .8$ \\
\hline Meyer [8] & 60 & 56 & 70 & $\mathrm{BMC}$ & 26 & $2460 \times 10^{6}$ & $51.3 \pm 9.3$ & $52 \pm 12.4$ & $50 \pm 10$ & $56.7 \pm 12.5$ \\
\hline $\operatorname{Li}[46]$ & 70 & 60 & 80 & $\mathrm{BMC}$ & 57 & $72.5 \times 10^{6}$ & $51 \pm 8.1$ & $52.6 \pm 5.7$ & $50 \pm 8.2$ & $57.1 \pm 7.8$ \\
\hline Kang [47] & 56 & 96 & 80 & BMC & Not Stated & $1500 \times 10^{6}$ & $53.2 \pm 13.3$ & $53.1 \pm 11.5$ & $52 \pm 9.9$ & $57.1 \pm 8.7$ \\
\hline Ge [48] & 20 & 58 & 90 & BMC & 16 & $38.7 \times 10^{6}$ & $58.2 \pm 7.5$ & $56.3 \pm 3.5$ & $53.8 \pm 9.2$ & $58.6 \pm 9.9$ \\
\hline Lunde [3] & 100 & 57 & 84 & $\mathrm{BMC}$ & Not Stated & $68 \times 10^{6}$ & $42.6 \pm 11.7$ & $49.3 \pm 11$ & $41.3 \pm 10.4$ & $49.3 \pm 13.2$ \\
\hline Schächinger [2] & 204 & 56 & 82 & $\mathrm{BMC}$ & 10 & $236 \times 10^{6}$ & $46.9 \pm 10.4$ & $49.9 \pm 13$ & $48.3 \pm 9.2$ & $53.8 \pm 10.2$ \\
\hline Meluzin [49] & 66 & 55 & 92.4 & BMC & 21 & $55 \times 10^{6}$ & $42 \pm 9$ & $44 \pm 9$ & $42 \pm 9$ & $45 \pm 9$ \\
\hline
\end{tabular}

$\mathrm{BMC}=$ Bone Marrow Cells.

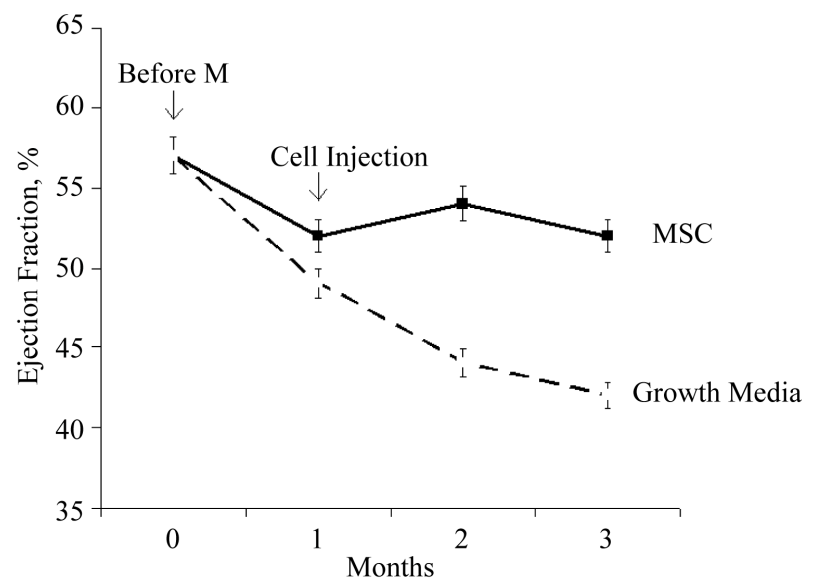

Figure 1. Stabilization of ejection fraction over time following intramyocardial injection of mesenchymal stem cells in the pig infarct model. Animals receiving the cells stabilized at an ejection fraction of $53 \%$ at 3 months compared to the untreated controls, which exhibited continued progressive decline to an ejection fraction of $42 \%$ (modified from reference [50]).

\section{THE PROBLEM OF CELL PERSISTENCE AT THE DELIVERY SITE}

After intramyocardial delivery of stem cells, only a few injected cells can be found at the delivery site. In the rat infarct model, only $15 \%$ of radio-labeled cells injected directly into the myocardium were found to be retained at one week [10], and when injected intravenously, no labeled cells were detected in the myocardium. In our own laboratory, we found $8 \%$ of injected labeled cells present at one day (White A., unpublished). Imaging of injected cells has revealed similar results [11]. Although the two potential mechanisms for cell disappearance are washout/migration from the injection site and cell death, the relative contributions of these and other factors has not been quantified.

\section{INCREASING CELL SURVIVAL BY MODIFYING THE CELL ENVIRONMENT}

Survival of injected stem cells is influenced by the recipient environment. Following myocardial infarction, the local environment is invaded by inflammatory cells. In addition to the underlying ischemic environment, cytokines expressed by these cells also promote apoptotic cell death. Consequently new strategies are aimed at reducing the expression of cytokines like tumor necrosis factor (TNF- $\alpha$ ) interleukins (ILs), matrix metalloproteinases and transforming growth factor- $\beta$ (TGF- $\beta$ ) that are natural regulators of apoptotic cell death [12]. One logical strategy is to counteract the pro-apoptotic influences by delivery of prosurvival cytokines. Among the most important regulators of apoptosis is the prosurvival Akt system [13]. For instance, erythropoietin-induced activation of the Akt system reduced post MI myocardial apoptosis by approximately $41 \%$ and infarct size by $7 \%$ in the rat model [14]. Other investigators have used growth factors to suppress apoptosis and stimulate proliferation. For example, in the rat infarct model, the growth factors IGF-1, FGF-2, and BMP-2 enhanced mesenchymal stem cell (MSC) survival and engraftment by $20 \%$ and $8 \%$, respectively, while simultaneously inducing their differentiation to cardiomyocytes [15]. Others have used environment modifying "cocktails". Laflamme et al. used a cocktail of 6 different agents to create an environment conducive to regeneration (Figure 2). Each agent was chosen to have a different beneficial function. ZVAD-fmk was used to inhibit caspase-induced apoptosis, cyclosporine and Bcl-XL peptide to block different mitochondrial death pathways, pinacidil to open ATP dependent K + channels, Matrigel 
to prevent anoikis, and insulin-like growth factor-1 (IGF1) to promote cell proliferation [16]. Co-injection of this cocktail with cardiomyocyte derived human ESCs resulted in 2.5 fold augmentation of left ventricular wall thickening compared to controls. We may speculate that environmental modification is a potent potential strategy, but among a long list of such candidate agents, the most clinically appropriate is yet to be defined.

\section{PRECONDITIONING AS A PROSURVIVAL STRATEGY}

An alternate strategy to improve cell survival is pretreatment of the cells prior to injection. For example, Pasha et al. found that preconditioning with stromal derived factor 1alpha (SDF-1), a CXCR4 receptor specific antagonist, may enhance the survival, proliferation and engraftment of the bone marrow derived mesenchymal stem cells. In vitro studies showed approximately 20\% improved cell viability, and an in vivo study in the rat MI model found $25 \%$ reduction in infarct size with use of the preconditioned cells compared to the control group [17]. Others have used hypoxic preconditioning. Cells that have undergone the process have a $20 \%$ relative increase in cell viability when subsequently exposed to a hypoxic environment. In the rat acute myocardial infarction model, preconditioned MSCs exhibited enhanced survival, which was accompanied by a $25 \%$ improvement in cardiac function compared to its control group. The authors attributed these improved outcomes to antiapoptotic and paracrine effects that increased the cells' potential for promoting neovascularization [18].

Preconditioning is also being tested using growth factors (Figure 3). Bartunek et al. pretreated MSCs with FGF, IGF-1, and bone morphogenetic protein-2 prior to injection in the chronic infarct large animal model. Preconditioning of MSCs led to higher expression of connexin-43 and gap junctions, and cell differentiation accompanied by significant increase in both area shortening and regional wall thickening observed at 4 and 12 weeks follow-up compared to unmodified cells [19]. The authors attributed these results to antiapoptotic effects and better intercellular communication.

We may conclude that since preconditioning involves only a relatively brief exposure of cells to a conditioning agent prior to injection, both environmental modification and preconditioning are amenable to incorporation into clinical practice, after the most appropriate agents are identified.

\section{GENETIC MODIFICATION PRIOR TO INJECTION AS A PROSURVIVAL STRATEGY}

A more complex method of preconditioning is genetic

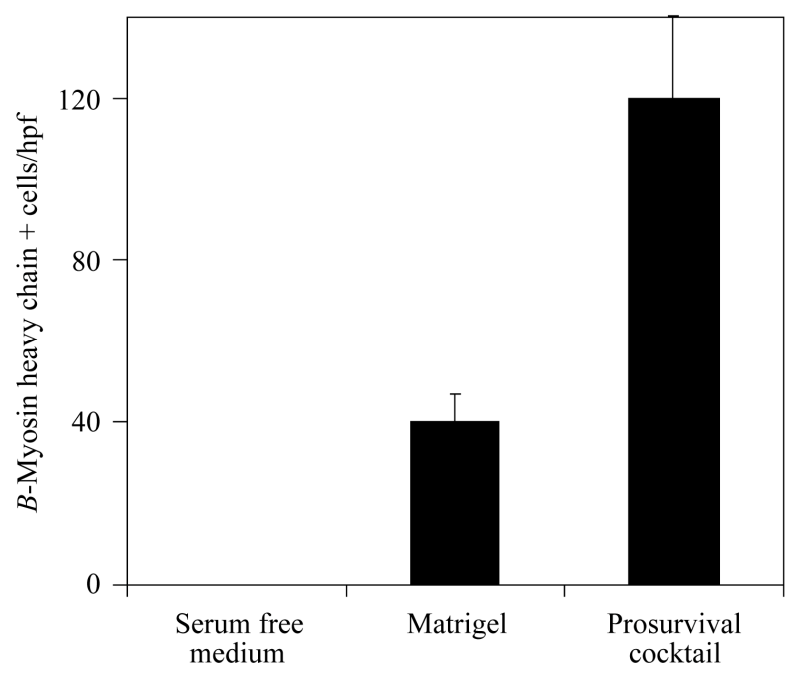

Figure 2. A prosurvival cocktail improves outcome measures in the rat infarct model. Human cardiomyocytes were transplanted in serum free medium alone, with a gelatinous extracellular mixture (Matrigel) or with Matrigel plus a cocktail of six pro-survival factors (Matrigel to prevent anoikis, a peptide from Bcl-XL to block mitochondrial death pathways, cyclosporine A to attenuate mitochondrial death pathways, pinacidil to mimic ischemic preconditioning, IGF-1 to activate Akt pathways and the caspase inhibitor ZVAD-fmk). No grafts were detected in any rats receiving the cells alone. All rats receiving cells in Matrigel-only or in the prosurvival cocktail developed a surviving graft of human myocardium. The prosurvival cocktail group exhibited approximately fourfold more $\beta$-myosin-positive graft cells than did the Matrigel-only group. These histologic findings were accompanied by better regional and global function in the treated groups (modified from reference [16]).

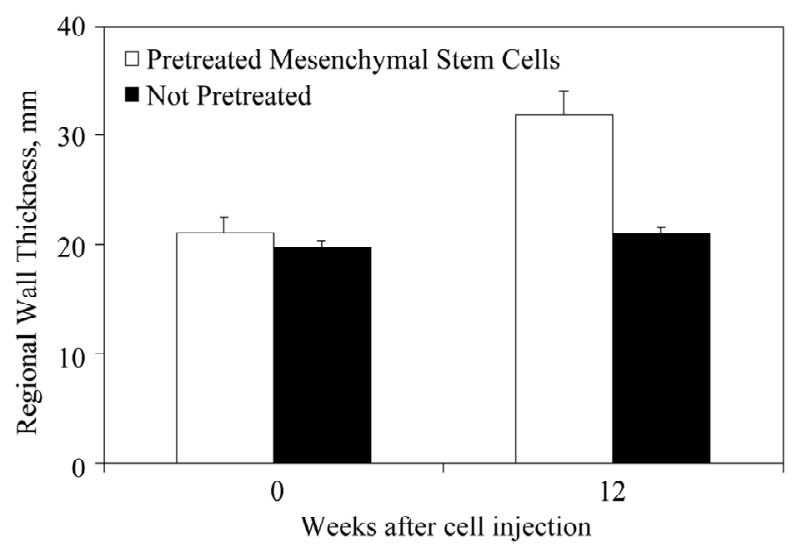

Figure 3. Preconditioning stem cells prior to injection increases their effectiveness. Autologous dog BMCs were preconditioned with the cardiomyogenic growth factors basic FGF, IGF-1, and bone morphogenetic protein-2. The cells were injected in a chronic dog MI model at $>8$ wk following coronary occlusion. The treatment group was compared to untreated MSCs. In the group that received the preconditioned cells, percent area shortening and left ventricular wall thickening in the infarct area was superior at 4,8 , and 12 weeks after cell transplant (modified from reference [19]). 
modification. Prior to injection, candidate cells can be modified to up regulate or down regulate the expression of certain desirable/undesirable genes. For instance Gnecchi et al. found that MSCs overexpressing Akt1 provided more cytoprotection than unmodified MSCs. Two weeks post-MI, rats treated with Akt-MSCs exhibited a significantly less increase in 2-DG uptake in the residual myocardium and functional recovery was inversely related to the level of uptake [20].

One of the most widely investigated prosurvival, proproliferative cytokines in cardiac stem cell therapy is insulin like growth factor-1 (IGF-1). MSCs transduced to overexpress IGF-1 increases the release of the antiapoptotic stromal cell-derived factor (SDF)-1, with concomitant increased mobilization of cardiac stem cells in the infarcted myocardium. These changes are accompanied by histologic evidence of enhanced cell survival, angiomyogenesis, significant reduction in infarct size with increased ejection fraction and fractional shortening compared to the controls [21]. The options for genetic modification, as with alteration of the cell environment and preconditioning, are numerous. For instance, MSCs genetically modified with the anti-apoptotic Bcl-2 gene also improves cell survival, engraftment, regenerative capacity and functional recovery of infarcted myocardium [22].

The relative efficacy of simple preconditioning and genetic modification has not yet been compared, and so the most effective method of preconditioning cells remains to be defined. Within these constraints we may speculate that the substantial magnitude of benefit reported with animal models suggests that the strategy will be worth testing in future clinical trials.

\section{INCREASING CELL PERSISTENCE AT THE INJECTION SITE}

Even if cells survive in the peri-infarct area, it seems likely that if myocardium is to regenerate, they must also persist in the area. Although the relative contribution of cell death and of cell washout to their rapid disappearance from the injection site has yet to be defined, both processes play a role. A number of strategies to increase cell persistence are under investigation. For example Simpson et al. applied a biodegradable patch consisting of collagen hydrogel mixed with hMSCs. When applied directly to the epicardial surface of infarcted myocardium, the patch resulted in $23 \%$ better initial engraftment of the MSCs and 30\% improved fractional shortening post-infarction [23]. An alternative strategy used by Takehara et al. was to suspend bFGF and human cardiosphere-derived cells (CDC) in biodegradable gelatin, in the pig model of chronic myocardial infarction, withintramyocardial injection. The biodegradable gelatin poly- ion complex with bFGF provided sustained delivery of bFGF accompanied by a $20 \%$ increase in CDC engraftment and $33 \%$ increase in autonomous human cardiomyocyte differentiation [24].

More complex strategies for providing cell scaffolding are also being tested. For instance, Davis et al. bioengineered a "biotin sandwich" technique in which biotinylated peptide nanofibers were used to deliver IGF-1 for 28 days post-injection [25]. Use of the IGF-1 tethered self-assembling peptide nanofibers with cardiac stem cells (CSC) in the rat infarct model induced 23\% higher number of newly formed myocytes compared to groups with CSC alone [26].

Other investigators are designing and fabricating scaffolds using elastase sensitive nanofibers. Wang et al. found that using scaffold incorporated microspheres encapsulating IGF-1 improved in vitro cell growth and survival under both normal and hypoxic conditions [27]. Thus methods to increase cell persistence are becoming available.

Strategies to stimulate persistence are being combined with those to increase cell survival and cell proliferation. For instance Takehara et al. suspended basic fibroblast growth factor (bFGF) in hydrogel. In the chronic, porcine MI model the bFGF-hydrogel medium injected without cells increased the formation of myocardial microvascular networks. When the bFGF/hydrogel mixture was injected with stem cells, engraftment and differentiation increased, accompanied by a $5 \%$ greater absolute ejection fraction and decreased infarct size at 4 weeks compared to controls [24].

At present, methods to increase cell persistence are largely confined to open heart or intramyocardial delivery, and do not seem applicable to intracoronary therapy. While transendocardial delivery in the cath lab is certainly feasible, it does add a major element of procedural complexity compared to intracoronary delivery. We may speculate that the problem of cell persistence is likely to remain a difficult issue for clinical intracoronary application.

\section{NEW STEM CELL TYPES}

Parallel with research on cell survival and persistence are efforts to develop new stem cell types. In principle, autologous stem cells remain the most suitable cell type because of their safety (reduced risk of tumorigenesis) and immunocompatibility.The early clinical trials which used skeletal myoblasts and both unfractionated bone marrow cells (BMC) and subfractions of the BMC population [28] satisfy these criteria. Development of new cell types is in part directed toward finding cells that may have a greater capacity to regenerate myocardium. From the diverse potential sources of cells which include adipose tissue, 
placental blood and spermatozoic tissue, we may identify two broad cell types that have commanded the greatest attention: cardiac stem cells and induced pluripotent stem cells.

\section{CARDIAC STEM CELLS AND CARDIOSPHERE DERIVED CELLS}

A small segment of the cells obtained at cardiac biopsy are cardiac stem cells (CSC) (Figure 4) [29-34]. These cells are now thought to be responsible for repopulation of the heart's cells over time, becoming myocytes, vascular cells or stromal cells. It is as yet unclear if these progenitor cells exist as a single population or as subpopulations of vascular and cardiac stem cells in the heart.

CSCs can be identified by use of antibodies, isolated and then cultured into millions of cells. When these cells are injected in the rat infarct model [35-37] they appear to regenerate myocardium. For example, Dawn et al. found that intravascular administration of CSCs inhibited LV remodeling, improved global and regional LV function and decreased infarct size [37]. Tang et al. confirmed these results, showing increased synthesis of myocardial protein by activating resident pluripotent c-kit+ CSCwhich in turn would generate new cardiac cells, leading to improved left ventricular function [35]. Others have found that intramyocardial injection of cardiac stem cells or growth factors in the healed scar tissue promotes cardiac repair and alleviates cardiac dysfunction [36]. CSCs are currently in clinical trial at the University of Louisville.

The Cardiosphere-Derived Autologous Stem Cells to Reverse Ventricular Dysfunction (CADUCEUS) trial [38] is a Phase I, randomized, dose escalation study of the

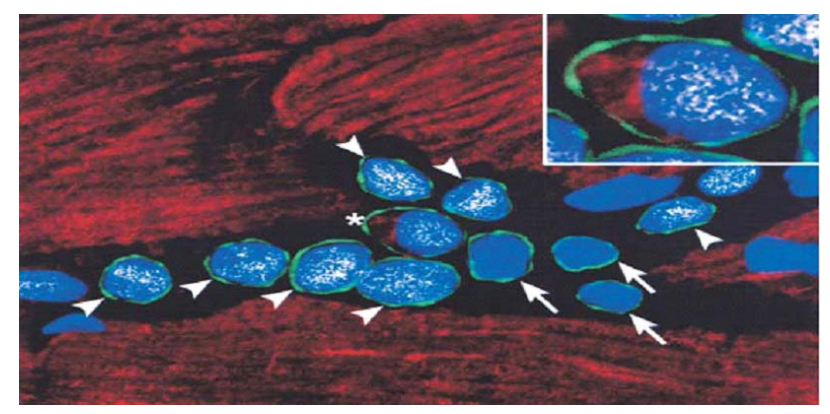

Figure 4. Documentation of the existence of a subpopulation of replicating myocyteswith the properties of cardiac stem cells in normal hearts. The stemness of these cells is established by the expression of the marker c-kit (arrow green rim of cells). These cells typically appear in niches within the myocardium. They are self-renewing, clonogenic, and multipotent, and capable of evolving into myocytes, smooth muscle, and endothelial cells. Intramyocardial injection of these cells results in formation of areas with differentiated myocardium, new vessels and myocytes (modified from reference [34]). intracoronary administration of autologous cardiospherederived stem cells in patients with a recent myocardial infarction. After 6 months the treated group showed reductions in scar mass compared to the control group. The CDC group also showed increases in viable mass, regional contractility and regional systolic wall thickening. However the changes in ejection fraction did not differ among the two groups by 6 months.

\section{HUMAN EMBRYONIC STEM CELLS AND INDUCED PLURIPOTENT CELLS}

Human embryonic stem cells (ESC) have been tested in animal myocardial infarction models. Kehat et al. found that human embryonic stem cells can differentiate into spontaneously contracting foci which have characteristics similar to the cardiomyocyte phenotype. These clusters of cells, known as embryoid bodies, exhibit electromechanical and structural properties identical to those seen in the early cardiomyocyte precursors [39]. In the rat infarct model, Rufaihah et al. injected hESC-derived CD133+ endothelial progenitor cells which were initially transduced with adenovirus containing hVEGF gene. The comparison with culture medium-injected control cells demonstrated enhanced myocardial angiogenesis, increased systolic function (61\% vs. 38\%) and reduction in infarct size (28\% vs. $76 \%$ ) [40].

Since use of human embryonic cells may encounter substantial resistance, a potentially major discovery is that stem cells closely resembling embryonic cells can be created from adult skin cells by nuclear reprogramming with factors that cause cells to revert to their original pluripotent state. Two research groups made this discovery at the same time [41-43]. One group reprogrammed the cell nucleus with the four stemming factors OCT3/4, SOX2, KLF4, and c-MYC [41]. The other used OCT4, SOX2, NANOG, and LIN28 [42]. The induced new cells possess a normal karyotype and are comparable to human embryogenic stem cells in their cell surface markers and their capability to form all the three primary germ layers.

The first intramyocardial injection of iPS cells in the mouse infarct model has been accomplished (Figure 5). It demonstrated substantial tissue regeneration, improved electromechanical functioning and increased ejection fraction (12\%) [41]. The potential advantages of such cells are substantial: they are autologous, easily obtained from the patient and are pluripotent. Nonetheless the use of this cell type in clinical trials is not yet on the near horizon. There are procedural issues of genetic stability and long term culture and the more serious issue of neoplastic potential. Novel attempts at improvement of iPS cell generation including use of small molecules and non-viral vectors in nuclear reprogramming are in early testing. 


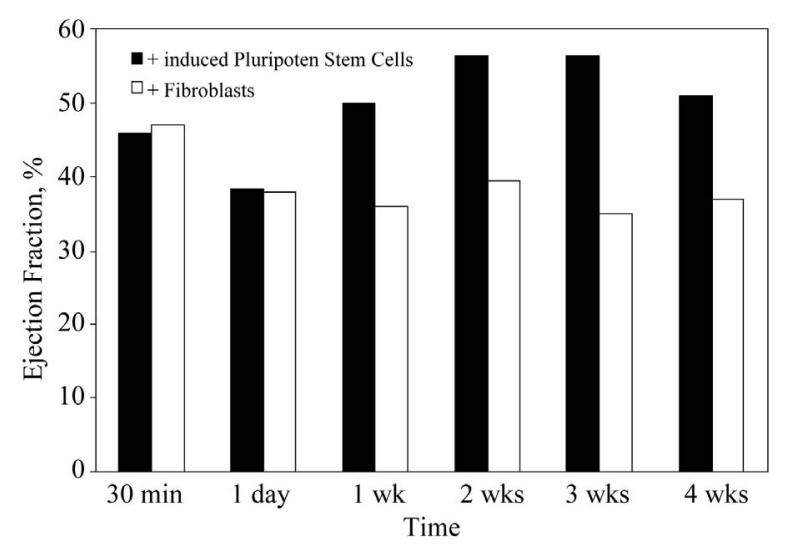

Figure 5. Effect of nuclear reprogrammed fibroblasts on left ventricular function following myocardial infarction. Fibroblasts were reprogrammed with human stemness factors (OCT3/4, SOX2, KLF4, and c-MYC) to create induced pluripotent stem cells. These cells were injected into infarct myocardium 30 minutes after coronary ligation. Substantial differences in both ejection fraction and infarct size at one week were observed in the treated group when compared to unmodified fibroblast-treated controls (modified from reference [41]).

\section{SUMMARY}

Despite its modest beginnings in clinical trials, cardiac stem cell therapy retains the promise of regenerating myocardium with resultant considerable clinical benefits. Since 2001, we have learned that tissue regeneration will not be achieved by the simple injection of stem cells into tissue. The solution to regeneration, if it becomes possible, now seems to lie in identifying multi-potent cells with the capacity for cardiac regeneration and developing strategies that will allow the cells to survive, persist and proliferate in a hostile environment.

\section{REFERENCES}

[1] Schachinger, V., Erbs, S., Elsasser, A., et al. (2006) Improved clinical outcome after intracoronary administration of bone-marrow-derived progenitor cells in acute myocardial infarction: Final 1-year results of the REPAIR-AMI trial. European Heart Journal, 27, 2775-2783. doi:10.1093/eurheartj/ehl388

[2] Schachinger, V., Erbs, S., Elsasser, A., et al. (2006) Intracoronary bone marrow-derived progenitor cells in acute myocardial infarction. The New England Journal of Medicine, 355, 1210-1221. doi:10.1056/NEJMoa060186

[3] Lunde, K., Solheim, S., Aakhus, S., et al. (2006) Intracoronary injection of mononuclear bone marrow cells in acute myocardial infarction. The New England Journal of Medicine, 355, 1199-1209. doi:10.1056/NEJMoa055706

[4] Janssens, S., Dubois, C., Bogaert, J., et al. (2006) Autologous bone marrow-derived stem-cell transfer in patients with ST-segment elevation myocardial infarction: Double-blind, randomised controlled trial. Lancet, 367, 113121.

\section{doi:10.1016/S0140-6736(05)67861-0}

[5] Chen, S.L., Fang, W.W., Ye, F., et al. (2004) Effect on left ventricular function of intracoronary transplantation of autologous bone marrow mesenchymal stem cell in patients with acute myocardial infarction. American Journal of Cardiology, 94, 92-95.

doi:10.1016/j.amjcard.2004.03.034

[6] Lipinski, M.J., Biondi-Zoccai, G.G., Abbate, A., et al. (2007) Impact of intracoronary cell therapy on left ventricular function in the setting of acute myocardial infarction: A collaborative systematic review and meta-analysis of controlled clinical trials. Journal of the American College of Cardiology, 50, 1761-1767. doi:10.1016/j.jacc.2007.07.041

[7] Lunde, K., Solheim, S., Forfang, K., et al. (2008) Anterior myocardial infarction with acute percutaneous coronary intervention and intracoronary injection of autologous mononuclear bone marrow cells: Safety, clinical outcome, and serial changes in left ventricular function during 12-months' follow-up. Journal of the American College of Cardiology, 51, 674-676. doi:10.1016/j.jacc.2007.10.032

[8] Meyer, G.P., Wollert, K.C., Lotz, J., et al. (2006) Intracoronary bone marrow cell transfer after myocardial infarction: Eighteen months' follow-up data from the randomized, controlled BOOST (BOne marrOw transfer to enhance ST-elevation infarct regeneration) trial. Circulation, 113, 1287-1294. doi:10.1161/CIRCULATIONAHA.105.575118

[9] Yousef, M., Schannwell, C.M., Kostering, M., et al. (2009) The BALANCE Study: Clinical benefit and longterm outcome after intracoronary autologous bone marrow cell transplantation in patients with acute myocardial infarction. Journal of the American College of Cardiology, 53, 2262-2269. doi:10.1016/j.jacc.2009.02.051

[10] Hale, S.L., Dai, W., Dow, J.S., et al. (2008) Mesenchymal stem cell administration at coronary artery reperfusion in the rat by two delivery routes: A quantitative assessment. Life Sciences, 83, 511-515. doi:10.1016/j.lfs.2008.07.020

[11] Li, Z., Lee, A., Huang, M., et al. (2009) Imaging survival and function of transplanted cardiac resident stem cells. Journal of the American College of Cardiology, 53, 1229. 1240. doi:10.1016/j.jacc.2008.12.036

[12] Forrester, J.S. and Libby, P. (2007) The inflammation hypothesis and its potential relevance to statin therapy. American Journal of Cardiology, 99, 732-738. doi:10.1016/j.amjcard.2006.09.125

[13] Cook, S.A., Matsui, T., Li, L., et al. (2002) Transcriptional effects of chronic Akt activation in the heart. Journal of Biological Chemistry, 277, 22528-22533. doi:10.1074/jbc.M201462200

[14] Klopsch, C., Furlani, D., Gabel, R., et al. (2009) Intracardiac injection of erythropoietin induces stem cell recruitment and improves cardiac functions in a rat myocardial infarction model. Journal of Cellular and Molecular Medicine, 13, 664-679. doi:10.1111/j.1582-4934.2008.00546.X

[15] Hahn, J.Y., Cho, H.J., Kang, H.J., et al. (2008) Pretreatment of mesenchymal stem cells with a combination 
of growth factors enhances gap junction formation, cytoprotective effect on cardiomyocytes, and therapeutic efficacy for myocardial infarction. Journal of the American College of Cardiology, 51, 933-943.

doi:10.1016/j.jacc.2007.11.040

[16] Laflamme, M.A., Chen, K.Y., Naumova, A.V., et al. (2007) Cardiomyocytes derived from human embryonic stem cells in pro-survival factors enhance function of infarcted rat hearts. Nature Biotechnology, 25, 1015-1024. doi:10.1038/nbt1327

[17] Pasha, Z., Wang, Y., Sheikh, R., et al. (2008) Preconditioning enhances cell survival and differentiation of stem cells during transplantation in infarcted myocardium. Cardiovascular Research, 77, 134-142. doi:10.1093/cvr/cvm025

[18] Hu, X., Yu, S.P., Fraser, J.L., et al. (2008) Transplantation of hypoxia-preconditioned mesenchymal stem cells improves infarcted heart function via enhanced survival of implanted cells and angiogenesis. Journal of Thoracic and Cardiovascular Surgery, 135, 799-808. doi:10.1016/j.jtcvs.2007.07.071

[19] Bartunek, J., Croissant, J.D., Wijns, W., et al. (2007) Pretreatment of adult bone marrow mesenchymal stem cells with cardiomyogenic growth factors and repair of the chronically infarcted myocardium. American Journal of Physiology-Heart and Circulatory Physiology, 292, H1095-H1104. doi:10.1152/ajpheart.01009.2005

[20] Gnecchi, M., He, H., Melo, L.G., et al. (2009) Early beneficial effects of bone marrow-derived mesenchymal stem cells overexpressing Akt on cardiac metabolism after myocardial infarction. Stem Cells, 27, 971-979. doi:10.1002/stem.12

[21] Haider, H., Jiang, S., Idris, N.M., et al. (2008) IGF-1overexpressing mesenchymal stem cells accelerate bone marrow stem cell mobilization via paracrine activation of SDF-1alpha/CXCR4 signaling to promote myocardial repair. Circulation Research, 103, 1300-1308. doi:10.1161/CIRCRESAHA.108.186742

[22] Li, W., Ma, N., Ong, L.L., et al. (2007) Bcl-2 engineered MSCs inhibited apoptosis and improved heart function. Stem Cells, 25, 2118-2127. doi:10.1634/stemcells.2006-0771

[23] Simpson, D., Liu, H., Fan, T.H., et al. (2007) A tissue engineering approach to progenitor cell delivery results in significant cell engraftment and improved myocardial remodeling. Stem Cells, 25, 2350-2357. doi:10.1634/stemcells.2007-0132

[24] Takehara, N., Tsutsumi, Y., Tateishi, K., et al. (2008) Controlled delivery of basic fibroblast growth factor promotes human cardiosphere-derived cell engraftment to enhance cardiac repair for chronic myocardial infarction. Journal of the American College of Cardiology, 52, 18581865. doi:10.1016/j.jacc.2008.06.052

[25] Davis, M.E., Hsieh, P.C., Takahashi, T., et al. (2006) Local myocardial insulin-like growth factor 1 (IGF-1) delivery with biotinylated peptide nanofibers improves cell therapy for myocardial infarction. Proceedings of the $\mathrm{Na}$ tional Academy of Sciences USA, 103, 8155-8160. doi:10.1073/pnas.0602877103
[26] Padin-Iruegas, M.E., Misao, Y., Davis, M.E., et al. (2009) Cardiac progenitor cells and biotinylated insulin-like growth factor-1 nanofibers improve endogenous and exogenous myocardial regeneration after infarction. Circulation, 120, 876-887. doi:10.1161/CIRCULATIONAHA.109.852285

[27] Wang, F., Li, Z., Tamama, K., et al. (2009) Fabrication and characterization of prosurvival growth factor releasing, anisotropic scaffolds for enhanced mesenchymal stem cell survival/growth and orientation. Biomacromolecules, 10, 2609-2618. doi:10.1021/bm900541u

[28] Shim, W.S., Jiang, S., Wong, P., et al. (2004) Ex vivo differentiation of human adult bone marrow stem cells into cardiomyocyte-like cells. Biochemical and Biophysical Research Communications, 324, 481-488. doi:10.1016/j.bbrc.2004.09.087

[29] Laflamme, M.A. and Murry, C.E. (2005) Regenerating the heart. Nature Biotechnology, 23, 845-856. doi:10.1038/nbt1117

[30] Scorsin, M., Hagege, A.A., Marotte, F., et al. (1997) Does transplantation of cardiomyocytes improve function of infarcted myocardium? Circulation, 96, II188-II193.

[31] Smith, R.R., Barile, L., Cho, H.C., et al. (2007) Regenerative potential of cardiosphere-derived cells expanded from percutaneous endomyocardial biopsy specimens. Circulation, 115, 896-908. doi:10.1161/CIRCULATIONAHA.106.655209

[32] Oh, H., Bradfute, S.B., Gallardo, T.D., et al. (2003) Cardiac progenitor cells from adult myocardium: Homing, differentiation, and fusion after infarction. Proceedings of the National Academy of Sciences USA, 100, 1231312318. doi:10.1073/pnas.2132126100

[33] Ott, H.C., Matthiesen, T.S., Brechtken, J., et al. (2007) The adult human heart as a source for stem cells: Repair strategies with embryonic-like progenitor cells. Nature Clinical Practice Cardiovascular Medicine, 4, S27-S39. doi:10.1038/ncpcardio0771

[34] Beltrami, A.P., Barlucchi, L., Torella, D., et al. (2003) Adult cardiac stem cells are multipotent and support myocardial regeneration. Cell, 114, 763-776. doi:10.1016/S0092-8674(03)00687-1

[35] Tang, X.L., Rokosh, G., Sanganalmath, S.K., et al. (2010) Intracoronary administration of cardiac progenitor cells alleviates left ventricular dysfunction in rats with a 30 day-old infarction. Circulation, 121, 293-305. doi:10.1161/CIRCULATIONAHA.109.871905

[36] Rota, M., Padin-Iruegas, M.E., Misao, Y., et al. (2008) Local activation or implantation of cardiac progenitor cells rescues scarred infarcted myocardium improving cardiac function. Circulation Research, 103, 107-116. doi:10.1161/CIRCRESAHA.108.178525

[37] Dawn, B., Stein, A.B., Urbanek, K., et al. (2005) Cardiac stem cells delivered intravascularly traverse the vessel barrier, regenerate infarcted myocardium, and improve cardiac function. Proceedings of the National Academy of Sciences USA, 102, 3766-3771. doi:10.1073/pnas.0405957102

[38] Makkar, R.R., Smith, R.R., Cheng, K., et al. (2012) In- 
tracoronary cardiosphere-derived cells for heart regeneration after myocardial infarction (CADUCEUS): A prospective, randomised phase 1 trial. Lancet, 13, 13.

[39] Kehat, I., Kenyagin-Karsenti, D., Snir, M., et al. (2001) Human embryonic stem cells can differentiate into myocytes with structural and functional properties of cardiomyocytes. Journal of Clinical Investigation, 108, 407414.

[40] Rufaihah, A.J., Haider, H.K., Heng, B.C., et al. (2010) Therapeutic angiogenesis by transplantation of human embryonic stem cell-derived CD133+ endothelial progenitor cells for cardiac repair. Regenerative Medicine, 5, 231-244. doi:10.2217/rme.09.83

[41] Nelson, T.J., Martinez-Fernandez, A., Yamada, S., et al. (2009) Repair of acute myocardial infarction by human stemness factors induced pluripotent stem cells. Circulation, 120, 408-416. doi:10.1161/CIRCULATIONAHA.109.865154

[42] Yu, J., Vodyanik, M.A., Smuga-Otto, K., et al. (2007) Induced pluripotent stem cell lines derived from human somatic cells. Science, 318, 1917-1920. doi:10.1126/science.1151526

[43] Behfar, A., Crespo-Diaz, R., Nelson, T.J., et al. (2010) Stem cells: Clinical trials results the end of the beginning or the beginning of the end? Cardiovascular \& Hematological Disorders Drug Targets, 10, 186-201.

[44] Strauer, B.E., Brehm, M., Zeus, T., et al. (2002) Repair of infarcted myocardium by autologous intracoronary mononuclear bone marrow cell transplantation in humans. Circulation, 106, 1913-1918. doi:10.1161/01.CIR.0000034046.87607.1C

[45] Bartunek, J., Vanderheyden, M., Vandekerckhove, B., et al. (2005) Intracoronary injection of CD133-positive enriched bone marrow progenitor cells promotes cardiac recovery after recent myocardial infarction: Feasibility and safety. Circulation, 112, 1178-1183.

[46] Li, Z.Q., Zhang, M., Jing, Y.Z., et al. (2007) The clinical study of autologous peripheral blood stem cell transplantation by intracoronary infusion in patients with acute myocardial infarction (AMI). International Journal of Cardiology, 115, 52-56. doi:10.1016/j.ijcard.2006.04.005

[47] Kang, H.J., Lee, H.Y., Na, S.H., et al. (2006) Differential effect of intracoronary infusion of mobilized peripheral blood stem cells by granulocyte colony-stimulating factor on left ventricular function and remodeling in patients with acute myocardial infarction versus old myocardial infarction: The MAGIC Cell-3-DES randomized, controlled trial. Circulation, 114, I145-I151. doi:10.1161/CIRCULATIONAHA.105.001107

[48] Ge, J., Li, Y., Qian, J., et al. (2006) Efficacy of emergent transcatheter transplantation of stem cells for treatment of acute myocardial infarction (TCT-STAMI). Heart, 92, 1764-1767. doi:10.1136/hrt.2005.085431

[49] Meluzin, J., Mayer, J., Groch, L., et al. (2006) Autologous transplantation of mononuclear bone marrow cells in patients with acute myocardial infarction: The effect of the dose of transplanted cells on myocardial function. American Heart Journal, 152, 975e9-975e15.

[50] Makkar, R.R., Price, M.J., Lill, M., et al. (2005) Intramyocardial injection of allogenic bone marrow-derived mesenchymal stem cells without immunosuppression preserves cardiac function in a porcine model of myocardial infarction. Journal of Cardiovascular Pharmacology and Therapeutics, 10, 225-233. doi:10.1177/107424840501000403 